\title{
Reseña de GONZÁLEZ VALENZUELA, Juliana. (2017). Bíos. El cuerpo del alma y el alma del cuerpo. México: Fondo de Cultura Económical Universidad Nacional Autónoma de México.
}

\author{
María Teresa Padilla Longoria
}

Ha salido a la luz la obra ponderada y producto de la madurez y literal disciplina filosófica de muchos años de Juliana González, Bíos. El cuerpo del alma y el alma del cuerpo, coeditada por el Fondo de Cultura Económica y la Universidad Nacional Autónoma de México. Con una prosa decantada y amena, pero no por ello, menos profunda y rigurosa, la autora hace suyo el método propio del filosofar socrático-platónico: el examen dialógico o dialéctico como duda metódica y renovada capacidad de asombro, teniendo como trasfondo la bioética.

Con toda honestidad y, por ende, sin ambages, la obra nos encara, en cada una de sus secciones, con profundos cuestionamientos, con la complejidad y retos de la relación y el entretejimiento de la ética, la antropología filosófica y la ontología con las ciencias de la vida.

Bíos consta de dos grandes apartados: uno dedicado a las reflexiones bioéticas y otro a la presencia de la filosofía. Con respecto al primero, la autora va diseccionando, concienzudamente, sus temáticas torales en un nutrido y variado conjunto de subsecciones. Haciendo gala de una cultura y conocimiento profundos del status questionis que va de la materia a la vida y de la vida a la libertad, Juliana González se replantea, parafraseando en forma y fondo, la interrogante de Max Scheler por el puesto del hombre en el cosmos, pero añadiendo la prospección contemporánea, a saber, las nuevas inquisiciones claves desde el ángulo y a la luz de la bioética y las neurociencias o, en otros términos y dicho de manera dubitativa y sucinta: ¿qué significa ser hombre en el presente?

De forma que, a juicio de la autora, el auténtico giro hacia la realidad espaciotemporal implica la expansión y el equilibrio, del que la bioética, en su función práctica, pueda dotar y conducir, a los avances de la ciencia y tecnologías de la vida y sus implicaciones prácticas de impronta moral, socio-política y jurídica, hacia fines racionales y, por tanto, favorables para la humanidad. Con ello se evitará adolecer 
de los males de las revoluciones biológicas que, so pretexto de evitar los dualismos, han sucumbido ante monismos y reduccionismos. En efecto, de lo que se trata es de hacer el movimiento de retrotracción al ámbito de la vida material y biológica de todo cuanto $\psi v \chi \eta ́$ comporta con vistas a que $\sigma \tilde{\omega} \mu \alpha$ se entienda cabalmente y en toda su extensión: como su matriz vital, esto es, su fuente nutricia, originaria, fundamental de existencia espacio-temporal, en una palabra, interdependiente.

Para ir más allá de dualismos y reduccionismos, Juliana González insiste en que la paradoja lógica se supera al afirmar, no sin asombro, rayano en el misterio, la realidad y la racionalidad de la contradicción onto-antropológica: la unidad-dual como coexistencia del dinamismo de la relación dependencia-independencia, continuidad-discontinuidad tanto de lo corpóreo como de lo mental al incorporar, sin negar la especificidad, la dimensión de la conciencia y de lo espiritual a la vida biológica.

El proceso metamórfico más sorprendente es el que va de la materia a la vida y de la vida a la libertad humana. Con humildad, destaca la autora, siempre hemos de renovar en nuestros días el $\theta \alpha \tilde{\mu} \mu \alpha$ filosófico-científico ante la extraordinaria recreación —en cuanto reactualización presente y operante- de la ars combinatoria que da lugar al milagro plástico de la vida. La vida, tal y como nos lo indican Erwin Schrödinger y Jesús Mosterín, es así, milagrosa novedad de ese bíos materia-energía, preñado de vitalidad. Hablar de bios es entender que sus rasgos definitorios son la complejidad, la excepcionalidad, la unicidad y la irreductibilidad. Más aún: es referirse al plus bio-mórfico de la particularidad en el seno de la universalidad de la materia físico-química. En suma, entender en profundidad lo que significa la vida implica comprenderla como el proceso metamórfico paradójico que ella reviste: como novedad ontológica que, sin desasirse de la materia físico-química universal, se organiza estructuralmente como materia viviente.

Asimismo, Juliana González presenta el largo proceso de evolución biológica y de humanización, en paralelo, tanto física como espiritual, del Homo sapiens: desde la adquisición de la posición bípeda y el conjunto de nuevas determinantes anatómicas que trae consigo, a saber, la ventaja de la perspectiva visual, el desarrollo del aparato fonador y, por ende, del lenguaje, la diferencia y provecho del pulgar oponible, la ampliación de la bóveda craneal y, por ello, el crecimiento del cerebro. Lo que nuestra autora quiere poner de relieve con todo esto es que el homo sapiens posee una naturaleza histórica en devenir o en proceso que nunca acaba de conformarse, pero que también puede involucionar y, con ello, deshumanizarse.

El proceso de humanización histórica, físico-espiritual del Homo sapiens implicó el refinamiento del cuerpo humano y la gradual adquisición de habilidades que se tradujeron en los desarrollos creativos de objetos útiles y herramientas que, a su 
vez, se concretaron en el descubrimiento y aplicación del fuego, de la agricultura, la caza, la pesca hasta el correlativo florecimiento de las facultades mentales y emocionales, de manera destacada en el lenguaje, que hizo posible la conciencia del mundo como realidad misteriosa y abanico abierto a la intercomunicación, el saber de la naturaleza humana y no humana, de la vida y de la muerte. Al respecto, en la obra se destaca lo que representó la verdadera revelación del arte rupestre como manifestación emblemática del devenir propiamente humano en la gestación y evolución de la conciencia, los conocimientos, las creencias, las excelencias perceptivas y la sorprendente sensibilidad artística y simbólica. De forma que el arte rupestre fungió como el aglutinante de la sabiduría estética con la técnica y de la ética con el sentido originario de religiosidad.

Con base en lo anterior, el texto pretende hacernos ver que genética y libertad no se contraponen, pues las implicaciones filosóficas que comporta el reconocimiento de los así denominados errores evolutivos son, por paradójico que pudiera parecer, determinantes biológicas de la libertad humana y, por ende, del $\lambda$ ófos, de

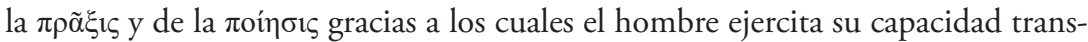
formativa de la naturaleza, de cultivo del mundo y de su propio mundo interior. Por ello, aunque el cerebro sea el órgano que coordina y controla la conducta de conformidad con el entorno y los impulsos congénitos, todo esto no es más que un acotamiento, pero no una determinación absoluta. El margen de acción en la deliberación y la decisión actúa en concomitancia con los genes, ya que de ellos depende la plasticidad cerebral programada para la libertad. Por tanto, la aparición del Homo sapiens constituyó una auténtica novedad ontológica, puesto que su identidad lo hace único e inconfundible en excelencia y dignidad y responsable ante el universo y ante sí mismo. ${ }^{1}$

Asimismo, la autora se arriesga a proponer que el continuo que va del mundo físico-químico al vivo es compatible con la teoría de la emergencia que sustenta la discontinuidad cualitativa de la evolución, cuyo fondo es el crecimiento continuo en complejidad que conduce al cambio de nivel.

Retornando a Heráclito (retroactivamente) y a Hegel, Juliana González habla de la comprensión dialéctica de la realidad como racionalidad armónica de contrarios y como vía para superar dualismos y monismos. Así, llega a la médula de su

${ }^{1}$ Aunque habrá que esperar todas las novedades que nos reporte la reconstrucción que se hiciera en Moscú en abril de 2018, en la Universidad Nacional de Ciencia y Tecnología (MIsIs) de la cabeza del Homo naledi, descubierto en Sudáfrica en el 2013 por el paleoantropólogo estadounidense Lee Berger. Lo que se sabe es que fue un homínido que convivió con los humanos y, con base en este dato, se podría cambiar por completo lo que hasta ahora sabemos sobre la evolución. 
propuesta, a saber, la necesidad de una ontología de la temporalidad y de la relatividad que comprenda al ser del hombre como un proceso abierto tanto de la gestación propia como de su ser en el mundo con vistas a superar los reduccionismos y los determinismos dimanantes de los avances biocientíficos y biotecnológicos. La autora es incisiva al respecto y nos muestra cómo la determinación para la indeterminación de la naturaleza natural es dialéctica o simultáneamente abierta, esto es, condicionada e incondicionada al mismo tiempo.

Por ello, se hace posible hablar del ethos en el Homo sapiens como una segunda naturaleza, a saber, de un carácter en donde reside la unidad indisoluble de naturaleza y espíritu, mente y cuerpo, necesidad y libertad, natura y cultura. La conclusión bioética que nuestra filósofa extrae de lo anteriormente dicho es que los genes y el cerebro constituyen el sustrato y la condición de posibilidad del alma. De esta manera redefine el enfoque con el cual debe entenderse la naturaleza humana: ésta es naturaleza moral e histórica; materia gris y psyché, universo plástico y creador de la cultura con sentido. Por tanto, el verdadero salto cualitativo hacia lo humano propiamente dicho, tanto de la physis exterior como de la interior, se da con la libertad como distintivo antropológico modal expresado en la conciencia, la voluntad, la valoración, la decisión y la transformación creadora de lo real. El hombre redimensiona la evolución biológica al introducir en ella los elementos espacio-temporales innovadores de la historia y del mundo.

Remitiéndose a la esperanza antropológica de Kant, Juliana González rescata la radicalidad del mal como inclinación humana que quedará subsumida a la originalidad del bien como predestinación más elevada. Por ello, la autora propone que el nuevo humanismo de hoy es de corresponsabilidad con todo el universo en su conjunto: de eco-ética. Éste comporta una soteriología “terrena” que se traduce en el cuidado de la vida (dicho de otro modo, la naturaleza) en todas sus modalidades. El nuevo humanismo está revestido de un ethos con una raigambre corporal del alma y con un vuelo anímico sobrenatural corpóreo. Aludiendo a Bertrand Russell, la obra nos abre a la idea de la contemplación como literal ciudadanía universal o bio-cosmopolitismo. Más aún: es en el repliegue, propiamente dicho, de la autognosis o reflexión de la vida sobre sí misma, cuando la evolución alcanza su coronamiento en la conciencia.

Hablar en nuestros días del genoma humano y de la naturaleza humana significa, a juicio de la autora, hacer una modificación de la condición ética del hombre como necesidad de elaborar una bioética filosófica. De manera que la

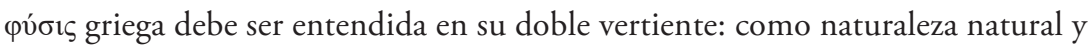

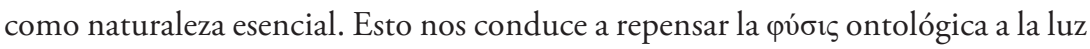

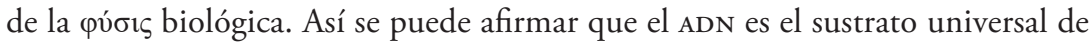


la vida tanto sincrónica como diacrónicamente hablando. Haciendo una retrospección heraclítea sería válido aseverar que el ADN es permanencia en el cambio, diversidad y unicidad. Esto es equivalente a afirmar que el genoma contiene un logos en el sentido profundo del vocablo griego: como orden y lenguaje. Juliana González arriesga todavía más: el ADN evidencia el misterio de la vida, la materia se hace vida sin dejar de ser materia, pero sin reducirse a ella. Por consiguiente, la vida humana se hace historia (ethos-cultura-libertad) sin dejar de ser vida. Es por el hombre que la vida deviene autoconsciente, pues al hablar de sí misma se torna conciencia viviente. El universo genómico también plantea problemas, uno de ellos, de carácter insoslayable, es el de la eugenesia: ¿cómo saber qué es lo que cabe mutar de nuestra naturaleza biológica si desconocemos qué es nuestra naturaleza ontológica?

Sin ambages la obra nos plantea el cuestionamiento sobre las implicaciones éticas y filosóficas de la medicina genómica. Es así que si la molécula de ADN es el sustrato universal de la vida, luego, simultáneamente, el genoma también es la clave de las diferencias individuales y únicas. Si el genoma de Homo sapiens es el mismo para cada ser humano, todo racismo queda invalidado biológica, ética y ontológicamente. La biotecnología ha de partir de la base de que todo ser vivo comparte una naturaleza común, lo cual entraña potencialidades médicas formidables. Pero, ¿cuáles son los riesgos de la medicina genómica? La autora enumera tres ineludibles: la invasión de la privacidad, la afectación de la autocomprensión y la intercomprensión de la vida humana, y la estigmatización poblacional. Asimismo, el para quién de la medicina genómica obliga a replantearse el clásico tema ético-ontológico sobre la naturaleza humana y el $\tau \dot{\lambda} \lambda$ os de lo humano. Parafraseando, mutatis mutandis, a Dostoievski, Juliana González dice: si no hay naturaleza humana, todo está permitido.

En el texto se hace hincapié en que hay una irreductibilidad del acto libre como

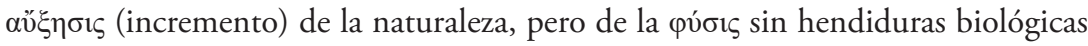
ni ontológicas. De ahí que una auténtica aproximación al cuerpo humano implique un rechazo tanto a los fanatismos cientificistas como a los fundamentalismos religiosos. La vida humana es un prodigio por la riqueza físico-espiritual que comporta y, por ello, debe ser entendida como misterio, como tensión acoplada de armonía de contrarios, al estilo del Efesio. Para concluir este apartado, la filósofa mexicana asienta que el mejoramiento humano, vía la medicina genómica, debe llevarse a cabo con vistas a la libertad y al nuevo humanismo.

Con respecto a la tecnología, el vínculo entre ética y bioética es propuesto en términos mítico-simbólicos. Así, el nuevo Titán biotecnológico es Prometeo desencadenado y deslumbrado por la nueva techné que terminará, por su post üßpıৎ, 
nuevamente encadenado. Tal y como reza el dicho: Dios perdona siempre, los hombres, a veces, la naturaleza jamás. Aludiendo al Protágoras de Platón, el texto resalta la lección del mito en el contexto del filósofo ateniense: sólo la auténtica vida ético-política puede salvar al hombre. La biotecnología nos enfrenta a la difícil ambigüedad de las promesas y amenazas por su potencial factibilidad. La vía que Juliana González propone es asumir el proceso tecno-científico irrefrenable, haciéndonos dueños de él al dotarlo de sentido ético y racional. Esto es: introducir valores y criterios de la razón práctica que conduzcan a la felicidad humana y, por ende, a la misión constructora de lo humano. En suma, hacer valer la razón ética es el sentido profundo y la auténtica misión de la bioética. De forma que la ética filosófica es insustituible por la perspectiva fundamental, reflexiva y universal de los problemas que sitúa en el contexto histórico pertinente. Asimismo, el libro sugiere repensar a Aristóteles con respecto al estatus ético-ontológico del embrión humano, replanteando la pregunta sobre la significación metafísica del ser en potencia. A juicio de la autora, la clave reside en entender al embrión como un ser en proceso que se va constituyendo, en dicho desarrollo embrionario, como mismidad, como permanencia en el cambio. Por lo tanto, nada le puede restar su significación de vida humana.

Con respecto a las razones filosóficas de una bioética laica, Juliana González esgrime que la vida es una en su diversidad y diversa en y por su unidad. Por consiguiente, la apelación a una ética y bioética laicas implica asumir actitudes racionales, plurales, inquisitivas y tolerantes.

En relación con la neuroética y la violencia se afirma que somos nuestro cerebro en el proceso temporal de evolución integradora que entraña. Si somos Homo sapiens sapiens ha de aflorar nuestra diferencia específica, porque nuestra naturaleza neuronal nos condiciona y proyecta, de manera antinómica, tanto para la no-violencia como para la violencia. Con vistas a evitar los monismos reduccionistas de Churchland y Dennet, así como los dualismos interactivos de Popper y Eccles, la autora propone que el mundo humano debe entenderse como espíritu encarnado y como cuerpo humano animado. En otras palabras, la neurobiología ha de ser comprendida en términos de plasticidad cerebral, esto es, en sus posibilidades de moldeamiento y autopoíesis experiencial, ambiental y ética. El hombre neuronal encuentra de nuevo, biológicamente hablando, su excelencia en la vida misma, en su naturaleza biológica que se define en la autotrascendencia recreativa. Hay que trabajar por y para la paz a fin de invertir la hegemonía de la violencia y convertirnos en artífices o poetas de la paz, cipevotorós.

En lo referente a los logros, promesas y amenazas nanotecnológicas, el libro reconoce que la nanotecnología nos ha abierto a un mundo cuasifantástico de po- 
sibilidades que, de no ejercerse con responsabilidad universal, correremos el riesgo de extinción de lo humano del Homo sapiens en su expresión más "nano sutil".

Respecto a la bioética y los derechos humanos la autora pone de relieve que la Declaración Universal de bioética y derechos humanos implica, por principio, el reconocimiento igualitario, respetuoso y solidario de la dignidad humana inalienable como la de una entidad personal autónoma, universal y libre.

En la segunda parte de Bios. El cuerpo del alma y el alma del cuerpo, Juliana González hace un recorrido de lo que ha constituido su itinerario filosófico con vistas a resaltar cómo está presente la filosofía en la vida en los contextos particu-

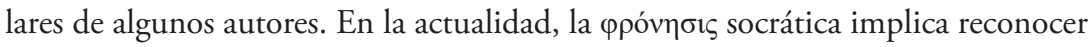

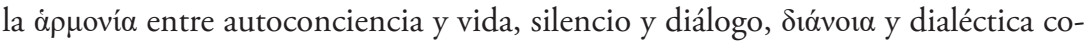
municativa, cuidado de sí y de los otros, examen interior y ż̀ $\varepsilon \gamma \chi o \varsigma$ agoral. De manera que el alma ética y el cerebro ético de las neurociencias constituyen una unidad interactiva indisoluble que proyecta la infinidad de estructuras y funciones del universo interior, pero, al mismo tiempo, su autonomía, independencia e irreductibilidad.

Kant es, a juicio de nuestra filósofa, referencia obligada para la bioética actual partiendo de las propias interrogantes fundamentales del filósofo de Könisberg: qué es el hombre y qué es la libertad. Vemos, asimismo, que en el Kant tardío hay una necesidad de efectuar una síntesis entre naturaleza y libertad, esto es, entre filosofía teórica y práctica. La autora apunta que, para el filósofo alemán, la historia se dirige hacia la realización de un ideal cosmopolita en la paz perpetua como sentido moral de la humanidad plasmados en la autonomía, la universalidad y la paz. En suma, la actualidad de Kant reside en una relectura de sus principios y conceptos éticos básicos para insertarlos en una ética para la bioética, verbigracia: la autonomía, la dignidad, el respeto, la humanidad y el juicio de reflexión que permiten la sana interacción bidireccional entre los parámetros éticos universales y la realidad concreta, diversa y móvil.

Juliana González propone recuperar para la bioética el trasfondo vital apolíneodionisíaco de Nietzsche como fenómeno ético-estético, a manera de conciliación milagrosa desde el fondo primordial, entre ambos, en la afirmación trágica en cuanto intensidad y sentido de vivir como héroe esperanzado. Es el sí originario a la vida de Zaratustra, del ser libre creadoramente y con sentido del para qué, en una frase, como fidelidad al sentido de la tierra.

El texto retoma de Freud el drama psíquico de la vida como drama moral, como crítica radical, pero al mismo tiempo configuradora del ethos y de la praxis moral contemporáneos: del resurgimiento del valor de la conciencia como esperanza única de salud y racionalidad moral con base en el rescate del fundamento radical 
de la naturaleza humana, esto es, en la tensión pulsional de la continuidad dinámica entre destino y carácter, entre eros y thánatos. De manera que Freud apunta con el psicoanálisis hacia la trascendencia ética, sin romper con la hondura unitaria de la psiquis.

Juliana González destaca de la obra de Amartya Sen las aporías de la economía y los caminos de la libertad en la denuncia clave de nuestro tiempo: el econocentrismo y la econo-cracia. La naturaleza de la economía se ha visto profundamente empobrecida por su alejamiento de la ética. La reforma de la economía y la recuperación de su esencia sólo serán posibles si abren al desarrollo procesal de la libertad y a la justicia y si la economía recupera su base racional. El gran desafío actual es cómo concretar el magno esfuerzo por hacer reales la justicia y la libertad.

Eduardo Nicol le permite poner en primer plano la concepción de una naturaleza humana dinámica, proteica, histórica, simbólica y, por ende, libre y misteriosa, pero también en terrible riesgo de sucumbir ante la necesidad aplastante y anónima de la razón de fuerza mayor.

La idea tensional armónica de contrarios del amor como ímpetu originario de la vida y como conciencia profunda de la historicidad del fenómeno amoroso mismo, es tomada de Octavio Paz, no sin dejar de resaltar su crisis y agonía en su más banal trivialización frívola: como barbarie tecnológica y mercantil en su cosificación anónima. Juliana González reasume la necesidad de rescatar el sentido "dialéctico" del amor en la vivacidad de su llama doble en la cual se descubre la unidad de la vida como lógica procesal viviente o poética en la constancia de su propia variación. Es así como, con base en la lectura del poeta mexicano, la autora vislumbra una nueva ética de la otredad en la temporalidad libre y responsable. Es por eso que la soledad laberíntica de Paz se torna apertura a la otredad del tú y del mundo que se encuentra en la comunidad originaria mítico-poética y amorosa de la unidad de y en lo diverso.

Cierro con tres observaciones y sugerencias. En primer lugar, sería posible incorporar a estas reflexiones, entre otros, la tradición presocrática temprana de Alcmeón de Crotona y la tardía de Diógenes de Apolonia. Alcmeón fue el primer pensador que sostuvo que el único ser con inteligencia/comprensión, бvvíqul, es el hombre, y que el centro coordinador y gobernante de todas las sensaciones es el cerebro. Esta tradición fue seguida por Diógenes de Apolonia y por Platón en el Timeo. En el medievo son notables, también, a este respecto, las aportaciones de Casiodoro.

En segundo lugar, y con respecto al estatus ético-ontológico del embrión humano. Habría que ser, a nuestro juicio, más preciso. Cuando se afirma: "Nada le puede restar [al embrión humano] su significación de vida humana" (González, 
2017: 118), no se le concede la condición de persona. Podría hacerse una distinción más fina y decirse que en el embrión humano hay una persona, mas no una personalidad. A este respecto, sería valioso incorporar la ya añeja discusión sobre el estatus del embrión humano de la tradición greco-latina, judeo-cristiana, bizantina y árabe.

Por último, al hablar de la fe y la razón (González, 2017: 129), Juliana González afirma que la primera no se discute. Ha habido simposios y reuniones muy fructíferas entre científicos (astrónomos, físicos, cosmólogos, biólogos, antropólogos, médicos) que profesan alguna religión y científicos que no. Eso implicaría entender la fe religiosa y la religiosidad en un sentido mucho más dinámico y crítico y como un proceso de búsqueda, y no exclusivamente como un conjunto de dogmas inamovibles.

Enhorabuena, Juliana González revitaliza la vocación filosófica con la aparición de Bíos. 